\title{
Analysis of Volatile-Phase Transport in Soils Using Natural Radon Gas as a Tracer
}

\author{
C. Chen* and D. M. Thomas
}

\begin{abstract}
We have conducted a field study of soil gas transport processes using radon gas as a naturally occurring tracer. The experiment monitored soil gas radon activity, soil moisture, and soil tremperature at depth; barometric pressure, rainfall, and wind speed were monitored at the soil surface. Linear and multiple regression analysis under natural environmental conditions are influenced by soil moisture content, barometric pressure variations, soil temperature, and soil structure. The effect of wind speed on subsurface radon activities under our field conditions has not been observed.
\end{abstract}

$\mathrm{R}$ ADIOACTIVE WASTES, pesticides, and other hazardous chemicals in both soil and groundwater are serious contaminant threats to our living environment. Our ability to contain, control, and treat these contaminants depends on our ability to understand the physical processes involved in their release, transport, and interaction with the subsurface environment. Volatile phase transport is a very important component of contaminant displacement and degradation in the unsaturated zone.

In recent years, a number of techniques have been applied to the investigation of the mechanisms of volatile phase transport of pollutants in the subsurface. Helium has been applied as a tracer gas in groundwater to detect diffusion and adsorption of gas-phase pollutants in the saturated zone (Dikum et al., 1975; Gupta, 1983; Davis et al., 1985; Gupta et al., 1990). Naturally occurring radon has also been recently monitored and modeled to better understand its mode of transport into dwellings where it, and its daughter products, can pose a health regard. Accumulated evidence and analyses also indicate that radon gas can be an effective tracer to investigate gas-phase transport under natural environmental conditions in field soils (Kraner et al., 1964; Tanner, 1964, 1980, 1988a, b; Schery et al., 1984; Cotter, 1990; Thomas et al., 1992; Tsang and Narasimhan, 1992);

This study was undertaken to further understand the application of natural subsurface radon variations to the analysis of the correlation between gas-phase transport and such soil and atmospheric variables as soil matric potential, temperature, barometric pressure, and wind speed.

\section{BACKGROUND}

Radon is a naturally occurring radioactive daughter product of the decay of naturally occurring uranium and thorium present in rocks and soils. There are 20 isotopes of radon known $\left({ }^{204} \mathrm{Rn}\right.$ to $\left.{ }^{224} \mathrm{Rn}\right)$; all are unstable and most have very short

Hawaii Inst. of Geophysics, School of Ocean and Earth Science and Technol., Univ. of Hawaii, 2525 Correa Rd., Honolulu, HI 96822. School of Ocean and Earth Science and Technology Contribution no. 3243. Received 21 Sept. 1992. *Corresponding author.

Published in J. Environ. Qual. 23:173-179 (1994). half-lives. Radon-222 (radon, with a half-life of $3.825 \mathrm{~d}$ ), ${ }^{220} \mathrm{Rn}$ (thoron, with a half-life of $54.5 \mathrm{~s}$ ), and ${ }^{21{ }^{9}} \mathrm{Rn}$ (actinon, with a half-life of $4.0 \mathrm{~s}$ ) are the three most common isotopes of radon. Due to its longer half-life and the abundance of its parent radionuclide, ${ }^{226} \mathrm{Rn}$ in the ${ }^{238} \mathrm{U}$ decay series, ${ }^{222} \mathrm{Rn}$ is the most commonly studied of the three isotopes. For this study, only ${ }^{222} \mathrm{Rn}$ has a half-life long enough for natural physical processes to affect its transport to the soil surface at the depth of interest to our study.

The physical processes that control the release and transport of radon in the environment have been studied for several decades (see Tanner, 1964, 1980, for excellent reviews of prior work). The results of these studies have found that emanation of radon from rocks and soils occurs by alpha recoil or diffusion (Fleischer, 1983). The emanation rate of radon depends primarily on the distribution of its parent ${ }^{226} \mathrm{Rn}$ with the soil and rock matrix, the microstructure of the rocks and soils, and environmental conditions. A microstructural view of the emanation process of radon in a granular aquifer indicates that grain-size distribution, grain-surface shape, and pore-water content are the controlling factors in radon release (Kraner et al., 1964; Andrews and Wood, 1972; Tanner, 1964, 1980; - Fleischer, 1963; Rama and Moore, 1984; Schery et al., 1984; Krishnaswami and Seidemann, 1988).

Unlike other volatile pollutants in the soil and atmosphere, radon is a chemically unreactive inert gas, and only moderately soluble in water. It is, however, highly mobile and responsive to physical processes that can affect volatile movement in soil. When soil is very dry (less than $20 \%$ moisture content, well below the soil field capacity), the emanation rate of radon from soil grains can be inhibited by a recoil-implantation process (Fleischer, 1983).

During the last several decades, several case studies have been conducted on subsurface radon activities that have evaluated the influence of soil and meteorological variables on soil gas radon activities. Kraner et al. (1964) made field observations and measurements of soil gas radon-222 concentrations as they varied in response to changes in precipitation, barometric pressure, wind speed, and soil temperature. The data analysis and interpretation indicated that the influence of precipitation, barometric pressure, high wind speed, and air temperature on radon flux in subsurface soil were very important. Limitations in the number and accuracy of the measurement did not allow a quantitative regression analysis to be performed. Measurements by Tanner (1988a) indicated that soil porosity and permeability and the degree of soil moisture saturation all play an important role in controlling radon migration. George (1981, p. 207) measured radon flux density at two sites, and it did not show good correlation with wind, pressure, and precipitation parameters by time-averaged values. Schery et al. (1984) conducted field measurements and simple model comparisons on radon exhalation from a gravelly sandy loam by focusing on radon flux density in the soil profile due to various meteorological variables. They concluded that variables such as temperature and wind speed were either comparatively small or undetectable. Goh et al. (1991) monitored radon activity in a soil mixed with different amounts of activated $C$ and martinet and found that moisture content and temperature were significant to the radon diffusion process. Their

Abbreviations: UHPAES, University of Hawaii Poamoho Agricultural Experimental Station; cph, counts per hour. 
results indicated a multiple relationship between radon concentration and variations in moisture content and temperature. Similarly, by using soil samples under controlled laboratory experiments, Washington and Rose (1992) concluded that radon transport was very sensitive to variation of soil moisture content and temperature. Based on these results and our longterm monitoring data in field, this study attempts to integrate radon activity with all of the important environmental variables through a quantitative regression analysis. We hope this work will lead to a better understanding of the mechanics of the interaction of environmental variables with the gas transport process.

\section{EXPERIMENT}

The field site for radon monitoring and data collection was located at the University of Hawaii Poamoho Agricultural Experimental Station (UHPAES). The soil at UHPAES is classified as a member of the Wahiawa Series silty clay, Oxisols (Green et al., 1982; Ikawa et al., 1985; Miller et al. 1988; Cotter, 1990). These Oxisols are principally derived from basaltic rock of alluvium and primarily composed of kaolinite and the oxides of $\mathrm{Fe}$ and $\mathrm{Al}$. The soil depth at this site is estimated to be at least $10 \mathrm{~m}$ and has been found to be uniform in gross chemical composition and particle-size distribution. Although the clay content is up to $90 \%$ in some soils that are highly structured, they are permeable and generally well drained. Cracks of various sizes, up to $5 \mathrm{~mm}$ in width, occur on the soil surface but vary seasonally due to changes of precipitation and soil water content. The crack profile, in terms of hydraulically effective macroporosity, usually exceeds $1 \mathrm{~m}$ in depth (Chen et al., 1993), but crop rooting is typically limited to the plow layer (about $45 \mathrm{~cm}$ ) because of the combination of low macroporosity in the $\mathrm{B}$ horizon and the development of tillage pans.

The field monitoring effort involved two separate monitoring arrays emplaced $20 \mathrm{~m}$ apart. Each array consisted of (i) three passive, electronic alpha particle detectors, (ii) three detectors (transducers) of soil matric potential, and (iii) two differential pressure probes (gas-phase pressure barometers). Each of the array instruments was buried at each of three depths: $0.8,1.3$, and $2.3 \mathrm{~m}$. The radon detectors recorded alpha decays integrated over minimum 15 -min intervals. One-hour integration intervals provided acceptable counting statistics and response data for our study. Barometric pressure, rainfall, temperature, and wind speed data of 1-h intervals were also recorded at the site (Cotter, 1990; Thomas et al., 1992).

The instrumentation used included:

1. Model 611 AlphaLogger, manufactured by AlphaNuclear Corporation of Mississauga, ON, for detection of alpha particles released by radon.

2. Ceramic disk sensors capable of measuring soil moisture levels in terms of matric potential and soil temperature (supplied by Aguatronics). Porous cup tensiometers were also employed for spot measurement of soil-water tension.

3. Honeywell 140PC series pressure gauge attached to a Hydronet Model 11 analog data recorder to monitor barometric pressure.

4. Sierra Misco Tipping Bucket rain gauge.

5. An R.M. Young Wind Sentry attached to the Hydronet Model 15 frequency logger to monitor wind speed and direction.

All recorded data were downloaded through a modem by a laptop computer (Cotter, 1990; Thomas et al., 1992).

\section{DATA ANALYSIS}

Some of the preliminary radon activity data from this study have been reported and discussed by Cotter (1990) and Thomas et al. (1992). They concluded that baro- metric pressure changes and rainfall events significantly affect the exchange of atmospheric air with soil (radon) gas. Field radon concentration was measured in counts per hour (cph). Field calibration indicated that $100 \mathrm{cph}$ is equivalent to approximately $5.9 \mathrm{~Bq} \mathrm{~L} \mathrm{~L}^{-1}\left(1.0 \mathrm{~Bq} \mathrm{~L} \mathrm{~L}^{-1}\right.$ $=1.0$ spontaneous nuclear transition per second per liter) in alpha particle activity (Cotter, 1990, p. 56). Figure 1 presents a record of radon (alpha) activity in terms of cph and rainfall events, which shows a synoptic radon response to these events and further supports the conclusions of Thomas et al. (1992). This study will further emphasize qualitative and quantitative analysis of the radon response to different site treatments between test and control arrays. All of the data sets are treated as variables in auto-correlation and cross-correlation tests for relationship and time lags between the dependent (Rn activity) and independent (barometric pressure, moisture content, temperature, and wind speed) variables. Finally, the multiple-regression method is applied to fit the relationship among those variables showing the greatest correlation with radon activity. Due to the effects on radon gas transport of interacting variables, such as matric potential, temperature, and barometric pressure, analysis of radon activities and each individual variable are presented to demonstrate our observation and interpretation, following our multiple regression analysis.

\section{Irrigation Treatments and Moisture Effects}

The test array was covered with a plastic sheet to prevent evaporation and vertical advection from exerting an influence on moisture and gas movement in the soil profile. Under the barrier, drip irrigation tubes were installed in a grid on the soil surface to provide a controlled source of soil moisture. We conducted three treatments on the test array in which drip irrigation water was added in an amount equivalent to precipitation of 50,100, and $416 \mathrm{~mm}$. All irrigations were applied with the same average intensity of approximately $378 \mathrm{~mm} \mathrm{~d}^{-1}$. The estimated saturated hydraulic conductivity of $142 \mathrm{~mm} \mathrm{~d}^{-1}$ (Chen et al., 1993) can be used as a reference for the soil at the site. Because the irrigation rate is higher than the soil-saturated hydraulic conductivity, the $416-\mathrm{mm}$ irrigation brought the soil moisture profile close to saturation from the topsoil surface to the depth of our deepest instrument-capping the soil profile above the deepest

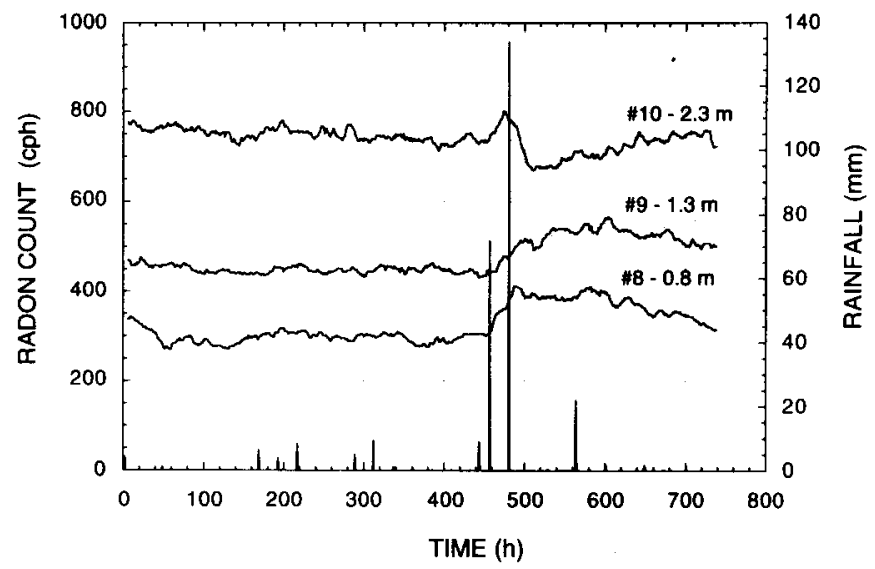

Fig. 1. Time measurements of radon counts at the 0.8-, 1.3-, and 2.3-m depth, and rainfall events. 
instrument (see data interpretation below. Figures 2 and 3 present the radon results for the test array, and provide comparison data from the control array. It is evident from a comparison of the radon activities at the test and control arrays (Fig. 2 and 3, respectively) that activities at the test array show a strong response to each of the three water additions to the soil. The responses are, however, different for each of the additions and at each of the three depths at which the detectors are placed. The important aspects of the response that we wish to consider are the following (i) during the first irrigation, the shallow activities, at 0.8 and $1.3 \mathrm{~m}$, show a moderate increase but the deeper activity is unaffected; (ii) during the second irrigation, the radon activities show an initial decline but subsequently increase to values greater than prior to treatment; and (iii) the final treatment brought about a substantial decline in activity that only gradually returned to values approaching the pretreatment activity. We believe that the response function observed can be explained by the physical processes associated with advection and diffusion of radon within and from the soil. At the control array, radon is free to diffuse or advect out of the soil in response to meteorological influences (see below). As has been long recognized (Kraner et al., 1964; Schery et al., 1984; Tanner 1964, 1980), the loss of radon from the soil (and addition of air to the soil gas) generates a concentration gradient of radon in the soil column that is evidenced in our study by the progressively increasing radon activity with depth in our test and control arrays. In our test array, however, we have attempted to inhibit advective processes by covering the array with a plastic sheet and, hence, the shallow activities are higher and the activity gradient is steeper than those found in the control array. Although this sheet inhibits vertical advection of gas, it is permeable to radon that can diffuse through the plastic membrane. Thus, vertical diffusion of radon from the soil still affects the radon activity at our test array.

When we apply the first irrigation treatment, the available soil voids and macropores for gas transport decrease due to hydration and expansion of the soil. As a result, gas diffusion to the soil surface and dispersion to the atmosphere, which is the primary pathway for removal of radon, is inhibited, and the radon concentration and concentration gradient of the wetted soil increases. As noted above, however, the deeper probe is located at a depth where diffusion to the soil surface has only a minimal impact on activities and, hence, radon is nearly at equilibrium with soil radium activities. At this depth, then, decreases in the permeability of the overlying soil will have only a minor impact on the soil gas radon content.

As saturation is approached, however, soil porosity floods, and radon transport shifts from advection and diffusion in air to diffusion in the liquid phase. Saturation of the micro and meso pores effectively reduces the surface area/volume ratio of the soil in contact with the gas phase (in which our probes monitor activity), and the activities would be expected to decline. The decrease in radon activities following the second and third irrigation treatments reflect the progressive saturation and drainage of the meso and micro pores in the soil column. That this process occurs in natural soils is demonstrated by the activity data presented in Fig. 1. The data recorded here show the radon activities during a series of intensive rainfall events for a soil that did not have a surface barrier. Under natural conditions, there is clearly a positive correlation between radon activities and soil moisture, but the relationship is neither linear nor unique since the transport processes can revert from one regime (gas phase) to another (liquid phase) as saturation is approached. We also found that a spectral analysis of the time series data (Matlab Signal Processing Toolbox by MathWorks, Inc.) found a variable time lag between radon response at depth and rainfall events (at the surface). We attribute this instability in lag to variations in the amount and intensity of precipitation and the preexisting soil moisture content in terms of matric potential.

Data in Fig. 4 and 5 show soil matric potential measurements as well as the radon variations at depths on 0.8 and $1.3 \mathrm{~m}$ during January 1991 (moisture data at the 2.3-m depth were not available due to frequent malfunctions of the instrument). Auto-correlation and crosscorrelation of the time series data (Matlab Signal Processing Toolbox) do not show a time lag between radon count and soil matric potential. It is evident from a visual inspection of Fig. 4 and 5 that radon activity and matric potential have an apparently strong crosscorrelation. The shapes and curvatures of the plots in Fig. 4 and 5 between radon count and matric potential are consistent: when matric potential goes down, the

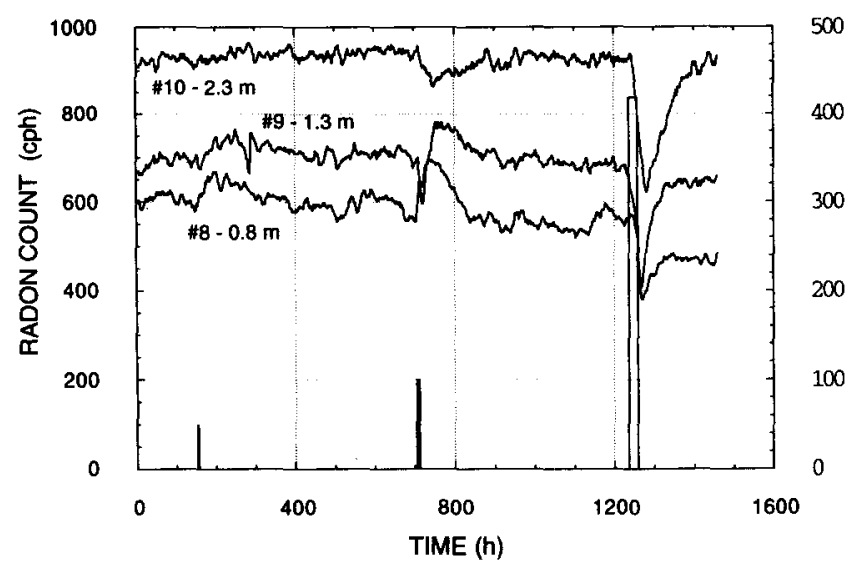

Fig. 2. Surface-covered measurement of radon count in response to irrigation events without evaporation.

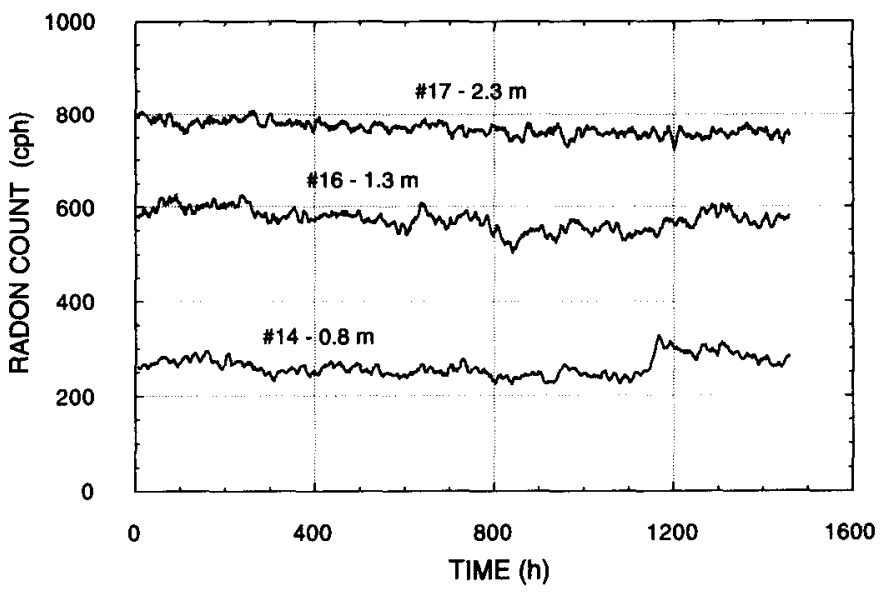

Fig. 3. Surface-open measurement of radon count without irrigation. 


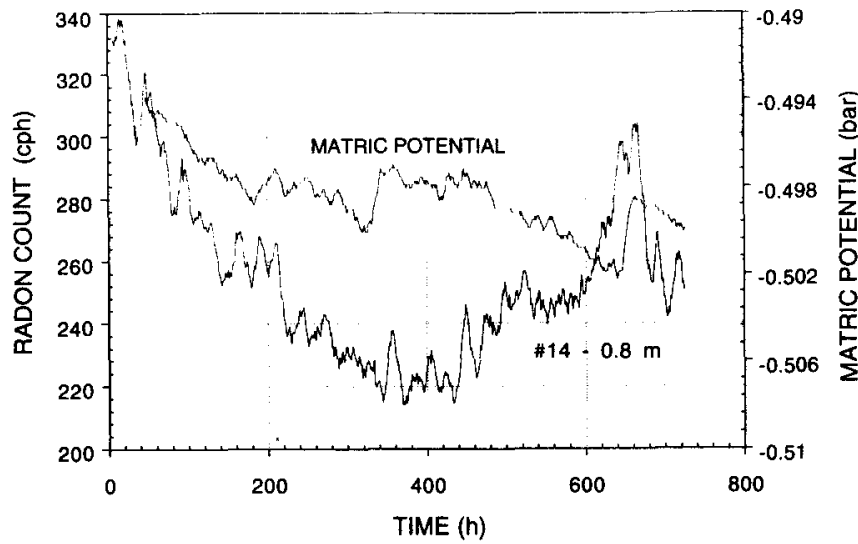

Fig. 4. Response of radon count to matric potential at the 0.8m depth.

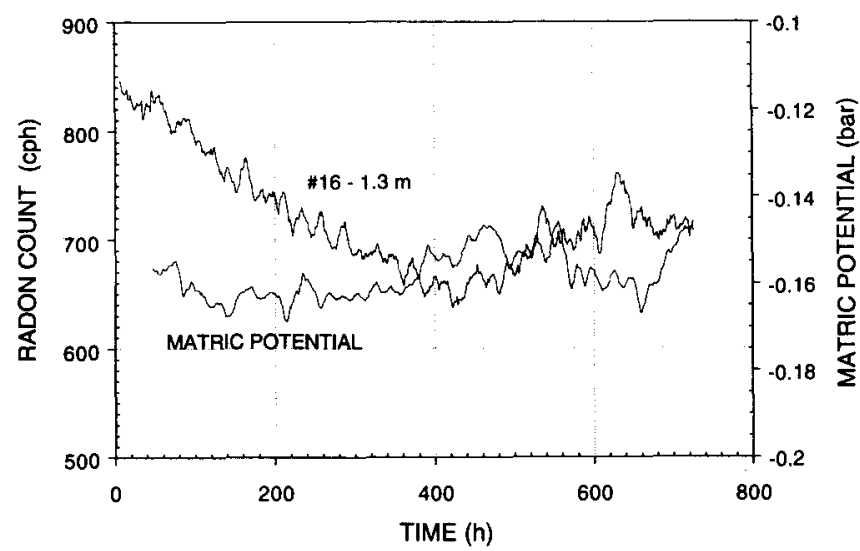

Fig. 5. Response of radon count to matric potential at the 1.3m depth.

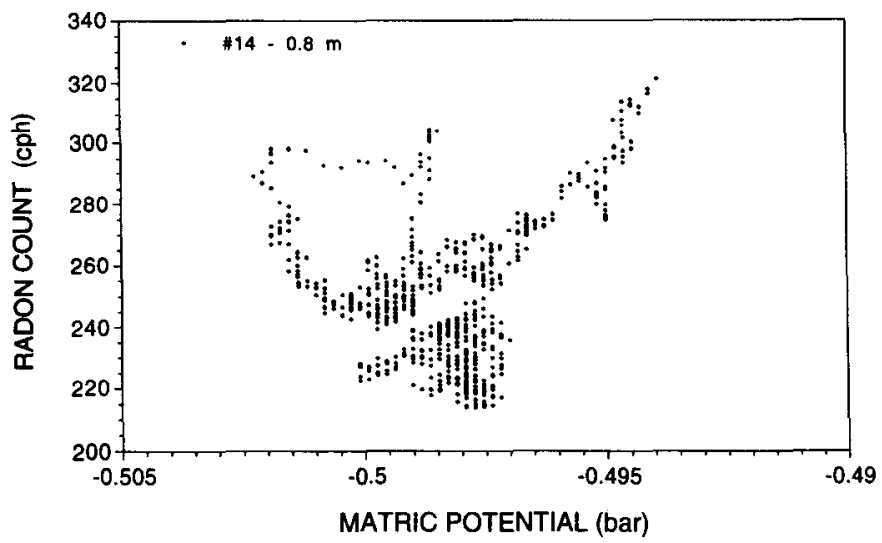

Fig. 6. Correlation of radon count against matric potential at the 0.8-m depth.

radon count decreases and when matric potential increases, radon activities also rise. In spite of the apparent close correlation between matric potential and radon activity, single regression analyses of radon count and the matric potential at depths 0.8 and $1.3 \mathrm{~m}$ (Fig. 6 and 7) show a low correlation coefficient $(R<6)$ and do not indicate a linear relationship between matric potential and radon activity. We believe that the absence of a linear relationship between matric potential and radon

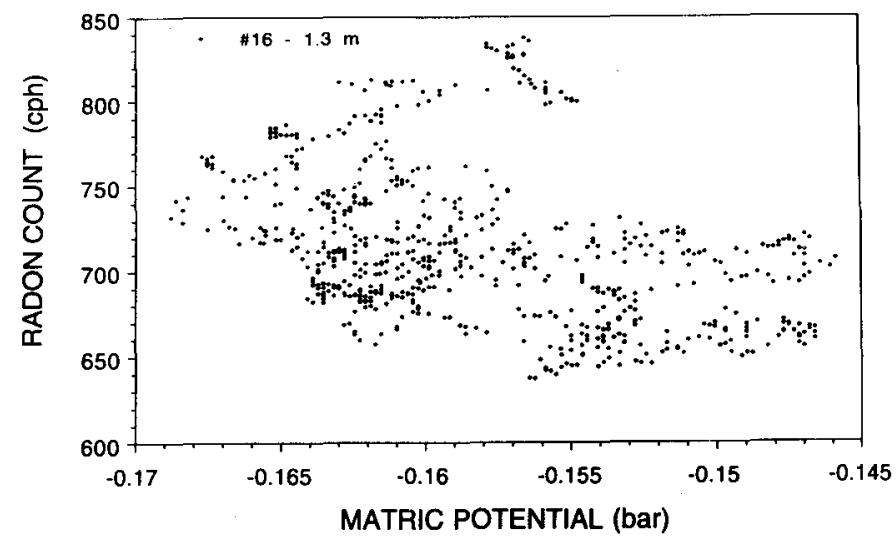

Fig. 7. Correlation of radon count against matric potential at the 1.3-m depth.

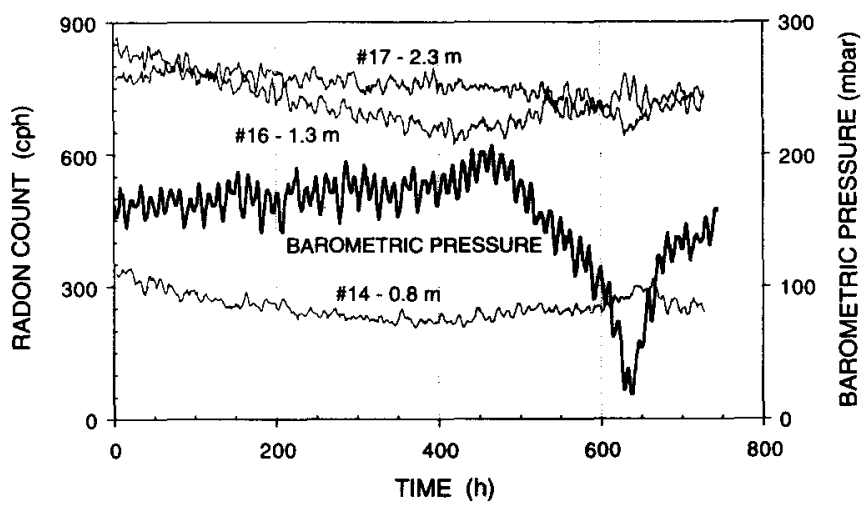

Fig. 8. Response of radon count to barometric pressure at the 0.8-, 1.3-, and 2.3-m depths.

activity is based not only on the fact that matric potential does not vary linearly with soil moisture but also because there are several other environmental variables that are concurrently affecting radon transport and activity in the soil (e.g., temperature and barometric pressure).

\section{Radon Counts in Response to Barometric Pressure}

Synoptic, weather-related changes in barometric pressure have been shown to displace the radon concentration profile downward or upward in response to, respectively, rising or falling barometric pressure (Kraner et al., 1964; Schery et al., 1984; Thomas et al., 1992). Figure 8 presents a monthly data interval for radon counts at depths $0.8,1.3$, and $2.3 \mathrm{~m}$ in response to barometric pressure. Careful observation of the plots of radon count and barometric pressure at both low (curvature and shape) and high frequencies indicates that the radon activities respond to atmospheric pressure changes at depths of 0.8 and $1.3 \mathrm{~m}$; a response at $2.3 \mathrm{~m}$ is less apparent.

This pressure response is the result of the compression and expansion of the soil gas column between the soil surface and the top of the local water table. As the gas column is compressed during rising atmospheric pressure, the radon gradient is forced downward, resulting in decreasing activities at a given depth, i.e., 0.8 and $1.3 \mathrm{~m}$ (Fig. 8). With falling atmospheric pressure, in general, the gradient extends upward and radon activities 
increase. The idealized radon gradient is steepest at the soil surface and progressively decreases with depth; the greatest change in activities with compression and expansion of the soil column should be observed at the shallowest depth. Our field data are consistent with this idealized model. Careful observation of Fig. 8 indicates that radon activity at $\mathbf{0 . 8} \mathrm{m}$ responded to minor fluctuations in barometric pressure. Only some of the radon activity at $1.3 \mathrm{~m}$ responded, probably because of rainfall events and soil moisture conditions, but the radon activity at $2.3 \mathrm{~m}$ does not show an apparent response. The high rates of soil ventilation implied by the pressure induced changes in radon activity in the shallow soils is believed to be the result of deeply penetrating drying cracks in the soil; a higher moisture content and the presence of a tillage pan may restrict the ventilation of the deeper soils. The results observed here are also consistent with the studies by Nilson et al. (1991) and Washington and Rose (1992).

An analysis of auto-correlation and cross-correlation functions for the barometric pressure-radon activity data did not find a significant lag time between the barometric pressure changes and the radon response function. A test of the strength of the regression coefficient between barometric pressure and radon activity showed a weak correlation coefficient of the individual independent variable (pressure) with the radon response (Fig. 9). We also note that there is an apparent difference in the response functions of radon at the two shallower soil depths and that at the deepest level monitored: the slopes of the regression lines for the former show a decreasing radon activity with increasing barometric pressure, whereas the deepest probe shows an increasing activity with increasing barometric pressure. Although it may be speculated that this is an artifact of a secondary relationship between barometric pressure and rainfall, we presently do not have a conclusive analysis for the observed trend of the deeper data.

\section{Temperature Effects}

Although seasonal air temperatures at our field site do not fluctuate as greatly as North American seasonal temperatures during the Hawaiian winter (December-February), diurnal and synoptic temperatures can change

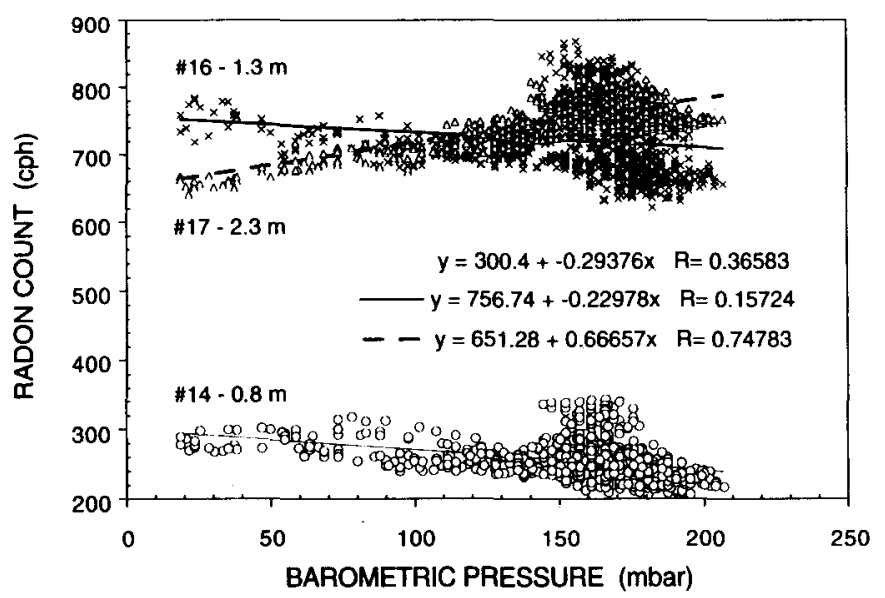

Fig. 9. Correlation of radon against barometric pressure at the 0.8-, 1.3-, and 2.3-m depths. sharply and frequently. A set of data for January 1991 showing soil temperature changes at $0.8 \mathrm{~m}$ and radon counts at the three depths is presented in Fig. 10. The data show an apparent low-frequency response of radon activity at the 0.8 and $1.3-\mathrm{m}$ depths to changes of the soil temperature at the $0.8-\mathrm{m}$ depth. Changes in activity at the 2.3-m depth in the soil do not show an obvious correspondence with temperature. The latter observation is attributed to the interseasonal stability of soil temperature at the 2.3-m depth.

Similar to the radon response to rainfall events and barometric pressure, the closer to the soil surface the radon detector was, the stronger was the observed response to changes in temperature. If it is assumed that the radon concentration at the surface is zero, the concentration gradients decreased between the soil surface and the $0.8-\mathrm{m}$ depth from about $350 \mathrm{cph} / \mathrm{m}$ depth to about $275 \mathrm{cph} / \mathrm{m}$, and between the $0.8-\mathrm{m}$ depth and the $1.3-\mathrm{m}$ depth from about $1040 \mathrm{cph} / \mathrm{m}$ to $880 \mathrm{cph} / \mathrm{m}$, when soil temperature at the $0.8-\mathrm{m}$ depth increased approximately from 21 to $22.5^{\circ} \mathrm{C}$. In contrast, the concentration gradient between the depths of 1.3 and $2.3 \mathrm{~m}$ increased from about 40 to $100 \mathrm{cph} / \mathrm{m}$ because radon at the $2.3-\mathrm{m}$ depth is deep enough to have a minimal impact from soil temperature change. We also note that the temperature influence on radon transport has a rather long period. At $0.8-\mathrm{m}$ depth, the maximum variation in the count rate during the interval monitored is about $30 \%$ of the average value, whereas at the $1.3-\mathrm{m}$ depth the range is less than $20 \%$ and at $2.3 \mathrm{~m}$ it is less than $15 \%$. Auto-correlation and cross-correlation did not show any time lag between the radon counts and the soil temperature changes due to the low frequency of the response function. These findings are consistent with the conclusion of the study by Washington and Rose (1992).

Gas phase phenomena are very sensitive to temperature changes, both as a result of the temperature dependence on diffusion and dispersion processes responsible for gas transport in the soil, as well as their influence over potential evaporation of soil moisture. An additional explanation for the observed relationship is that increasing soil temperature reflects increasing evaporative loss of moisture from the soil and increasing gas-filled porosity available for soil gas exchange with atmospheric air.

Single regression results are present in Fig. 11. The

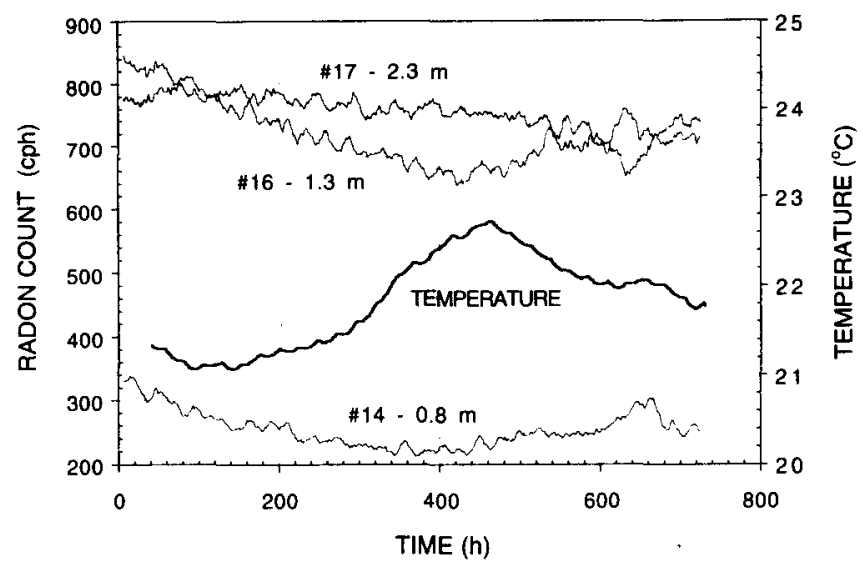

Fig. 10. Response of radon count at the 0.8-, 1.3-, and $2.3-\mathrm{m}$ depths to soil temperature at the $1.3-\mathrm{m}$ depth. 


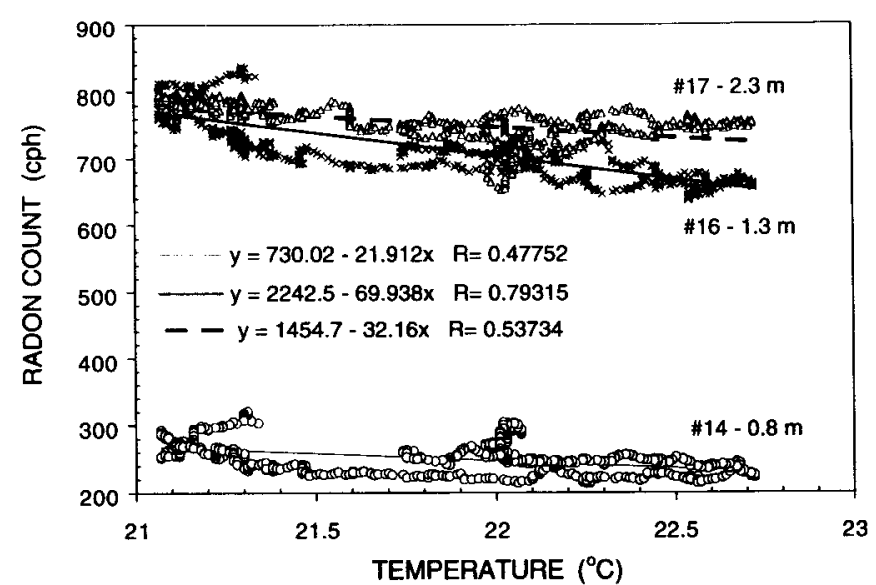

Fig. 11. Correlation of radon count at the 0.8-, 1.3-, and 2.3m depths to soil temperature at the 1.3-m depth.

correlation coefficient of radon count at the 1.3-m depth vs. the soil temperature at the $0.8-\mathrm{m}$ depth is higher than the other two, which supports our interpretation of the above temperature-gradient-driven phenomena. From the regression results and physical processes we can conclude that temperature change in soil plays a very important role in radon gas transport, but a single regression between radon concentration and soil temperature cannot represent the entire process of radon transport in soil.

\section{Wind Speed and Direction}

Cross-correlation tests performed on wind speed and wind direction did not find a statistically significant effect on advective radon transport. We can identify two possible reasons for the apparent absence of influence: (i) we may not have found an appropriate method of segregating wind speed and wind direction effects from the other environmental conditions that affect soil gas advection and radon transport; or (ii) wind-driven pumping effects may be effective only when the surface topography and wind direction interact in a manner than enhances subsurface advection. Additional experiments are underway to further investigate these relationships.

\section{Multiple Regression}

The foregoing data analyses and discussions have demonstrated that radon gas transport is sensitive to changes in soil moisture, barometric pressure, and soil temperature. Goh et al. (1991) also reported a multiple relationship between radon concentration and independent variables of moisture content and temperature from their monitoring experiments of radon in soils and in the adjacent substructures of buildings. They found that moisture content controls the available space in the soil for gas transport; as long as open pores are available, fluctuation of barometric pressure and temperature induces changes in radon transport in terms of diffusion, dispersion, and convection through soil. The higher frequency spectrum of the barometric pressure changes, however, contributes a greater effect on the radon gas flux by air pumping than does the lower frequency temperature change.

Even though we have found that the radon data show reasonably strong correlations with these environmental
Table 1. List of correlation coefficients by multiple regression between radon count and variables of soil matric potential, barometric pressure, and temperature at 0.8- and 1.3-m depths for the data set of January 1991.

\begin{tabular}{rlcc}
\hline Detector & Array & Depth & Correlation coeff., $R$ \\
\hline & & $\mathrm{m}$ & \\
8 & Control & 0.8 & 0.75 \\
9 & Control & 1.3 & 0.81 \\
14 & Test & 0.8 & 0.77 \\
16 & Test & 1.3 & 0.84 \\
\hline
\end{tabular}

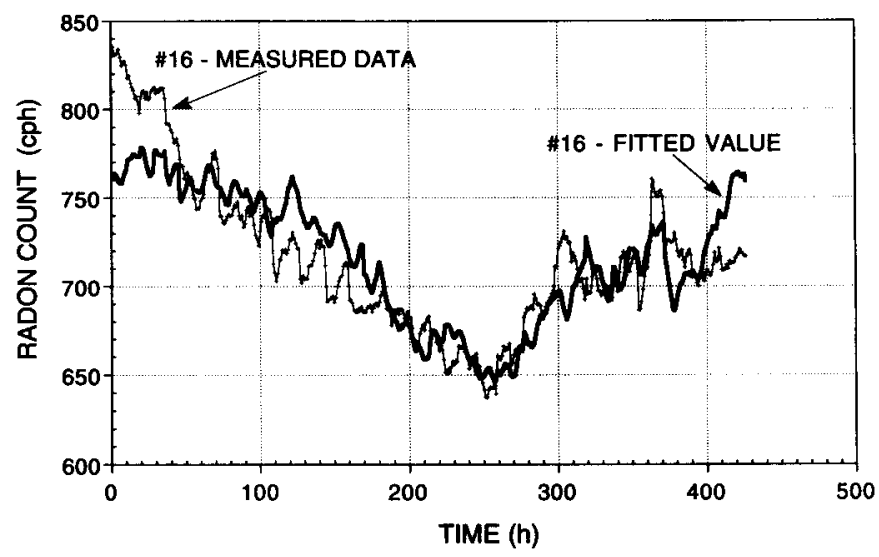

Fig. 12. Radon comparison of measured data and fitted value by multiple regression with variables of matric potential, barometric pressure, and temperature at the 1.3-m depth.

variables, the small individual correlation coefficients that were calculated for the independent variables suggests that multiple regression analysis could provide a better correspondence between field data and calculated radon activities. Because our results did not indicate a significant time lag effect in the individual correlations, this factor need not be considered and multiple regression can be easily conducted using StatView, a computer software program. A set of data for January 1991 was used as an example here. Table 1 presents the results of the multiple regression analysis. The correlation coefficient is sufficiently high to ensure that the regression line follows the data with only minor deviation between the field data and the calculated curve. Figure 12 presents a fitting of the measured radon data by using the multiple regression for a $30-d$ period. We note that, because of the observed nonlinearities in the radon response function and the complex relationships between variables, direct application of the regression equation to other soil and meteorological conditions does not yield an accurate prediction of temporal variations in subsurface radon activities.

\section{DISCUSSION AND SUMMARY}

Although gas phase transport plays an important role in volatile contaminant movement in the subsurface, the complexity of soil physical properties and their response to external weather conditions currently restricts our modeling efforts to the simplest and most ideal situations. Regression analyses of soil gas radon activity data vs. meteorological and soil property data have allowed us to identify qualitative deviations from idealized models 
of air exchange with soil gas. The results of this investigation have demonstrated how environmental conditions individually and interactively affect the physical processes that control radon transport in the soil and, ultimately, the concentration profile of radon in the soil gas. We hope continuing investigations of the radon transport process will allow us to develop a more comprehensive model of these processes that can accurately model the transport of radon and other volatile contaminants in the soil.

\section{REFERENCES}

Andrews, J.N., and D.F. Wood. 1972. Mechanism of radon release in rock matrices and entry groundwaters. Trans. Inst. Min. Metall. Sec. B:197-209.

Chen, C., D.M. Thomas, R.E. Green, and R.J. Wagenet. 1993. Two-domain estimation of hydraulic properties in macropore soils. Soil Sci. Soc. Am. J. 57:680-686.

Cotter, J.M. 1990. Simulated transport of radon in soil gas. M.S. thesis, Univ. of Hawaii, Honolulu, HI.

Davis, S.N., D.J. Campbell, N.W. Bently, and T.J. Flynn. 1985. Groundwater tracers. National Water Well Assoc., Worthing ton, OH. p. 122-124. Robert S. Kerr Environ. Res. Lab., Office of Res. and Development, USEPA, Ada, OK.

Dikum, A.V., V.M. Korobeynic, and I.N. Yanitskiy. 1975. Some indications of existence of transcrustal gas flow. Geochem. Int. 12(6): 73-78.

Fleischer, R.L. 1983. Theory of alpha recoil effects on radon release and isotopic disequilibrium. Geochim. Cosmochim. Acta 47:779-784.

George, R.L. 1981. Radon flux measurements. EML Resp. 399. National Tech. Inf. Service, Springfield, VA.

Goh, T.B., D.W. Oscarson, M. Cheslock, and C. Shaykewich. 1991. Fluence rate of radon from soil: Effect of sorption barriers, moisture content, and temperature. Health Phys. 61:359 365.

Green, R.E., L.R. Ahuja, S.K. Chong, and L.S. Lau. 1982. Water conduction in Hawaii oxic soils. Tech. Rep. 143. Univ. Hawaii Water Resour. Res. Center, Univ. of Hawaii at Manoa, Honolulu, HI.

Gupta, S.K. 1983. Design of an ion pump based analyzer for geological investigations. Curr. Sci. 52:469-471.

Gupta, S.K., L.S. Lau, P.S. Moravik, and A. El-Kadi. 1990. Injected helium: A new hydrological tracer. National Science Foundation Project Completion Rep., Project CES-8818175. Univ. Hawaii Water Resour. Res. Center, Univ. of Hawaii at Manoa, Honolulu, HI.

Ikawa, H., H.H. Sato, A.K.S. Chang, S. Nakamura, E. Robello,
Jr., and S.P. Periaswamy. 1985. Soils of Hawaii agricultural experiment station, University of Hawaii: Soil survey, laboratory data, and soil descriptions. BSP Tech. Rep. 4. HITAHR Res. Ext. Ser. 022. Univ. of Hawaii, Honolulu, HI.

Kraner, H.W., G.L. Schroeder, and R.D. Evans. 1964. Measurements of the effects of atmospheric variables on radon-222 flux and soil-gas concentrations. p. 191-215. In J.A.S. Adams and W.M. Lowder (ed.) Univ, of Chicago Press, Chicago, IL.

Krishnaswami, S., and D.E. Seidemann. 1988. Comparative study of ${ }^{222} \mathrm{Rn},{ }^{40} \mathrm{Ar}$ and ${ }^{37} \mathrm{Ar}$ leakage from rocks and minerals: Implications for the role of macropores in gas transport through natural silicates. Geochim. Acta 52:655-658.

Miller, M.E., R.E. Green, F.L. Peterson, R.C. John, and K. Loague. 1988. Hydrogeologic characteristics of subsoil and Saprotlite and relationship to contaminant transport, central Oahu, Hawaii. Tech. Rep. 178. Univ. Hawaii Water Resour. Res. Center, Univ. of Hawaii at Manoa, Honolulu, HI.

Nilson, R.H., E.W. Peterson, and K.H. Lie. 1991. Atmospheric pumping: A mechanism causing vertical transport of contaminated gases through fractured permeable media. J. Geophys. Res. 96(B13): 21933-21948.

Rama, and W.S. Moore. 1984. Mechanism of transport of U-Th series radioisotopes from solids into groundwater. Geochim. Cosmochim. Acta 48:395-399.

Schery, S.D., D.H. Gaeddert, and M.H. Wilkening. 1984. Factors affecting exhalation of radon from a gravelly sandy loam. J. Geophys. Res. 89(D5):7299-7309.

Tanner, A.M. 1964. Radon migration in the ground: A review. p. 161-190. In J.A.S. Adams and W.M. Lowder (ed.) The natural radiation environment. Univ. of Chicago Press, Chicago, IL.

Tanner, A.B. 1980. Radon migration in the ground: A supplementary review. p. 5-56. In T.F. Gesell and W.M. Lowder (ed.) The natural radiation environment III. DOE Symp. Ser. i.

Tanner, A.B. 1988a. A tentative protocol for measurement of radon availability from the ground. Northeastern Environ. Sci. 7:58-62.

Tanner, A.B. 1988b. Measurement of radon availability from soil. p.139-146. In M.A. and R.H. Hansman (ed.) Proc. of the GEORAD Conference, St. Louis, MO. Missouri Dep. Nat. Resour., Div. Geology and Land Survey Spec. Publ. 4. Missouri Dep. of Nat. Resour., Rolla, MO.

Thomas, D.M., J.M. Cotter, and D. Holford. 1992. Experimental design for soil gas radon monitoring. J. Radioanal. Nucl. Chem. 96(2):313-323.

Tsang, Y.W., and T.N. Narasimhan. 1992. Effects of periodic atmospheric pressure variation on radon entry into buildings. J. Geophys. Res. 97(B6):9161-9170.

Washington, J.W., and A.W. Rose. 1992. Temporal variability of radon concentration in the interstitial gas of soils in Pennsylvania. J. Geophys. Res. 97(B6):9145-9159. 